\title{
高出力エキシマレーザーを用いたパルスレーザー 堆積法で作製した酸化インジウムスズ透明導電膜*
}

\author{
鈴木 晶雄*1. 守 昭人*1. 坂本 淳*1. 谷 善之*1 \\ 青木 孝憲*1・松下 辰彦*1 $\cdot$ 奥田 昌宏*2 \\ （受理2001年11月22日，揭載決定2002年 2 月 2 日）
}

Transparent Conducting Indium Tin Oxide Films Prepared by

Pulsed Laser Deposition Using High Power ArF Excimer Laser

\begin{abstract}
Akio SUZUKI*1, Akihito MORI*1, Jun SAKAMOTO*1, Yoshiyuki TANI*1, Takanori AOKI*1, Tatsuhiko MATSUSHITA*1 and Masahiro OKUDA*2

${ }^{* 1}$ Department of Electrical Engineering and Electronics, College of Engineering,

Osaka Sangyo University, 3-1-1 Nakagaito, Daito, Osaka 574-8530, Japan

${ }^{*}$ Department of Physics and Electronics, College of Engineering, Osaka Prefecture University, 1-1 Gakuen-cho, Sakai, Osaka 593-8531, Japan
\end{abstract}

(Received November 22, 2001, Accepted February 2, 2002)

\begin{abstract}
$\mathrm{In}_{2} \mathrm{O}_{3}$ doped with $5 \mathrm{wt} \% \mathrm{SnO}_{2}$ (indium-tin oxide (ITO) (5 wt \%) ) films were deposited on glass substrates by pulsed laser deposition using an ArF excimer laser $(\lambda=193 \mathrm{~nm})$. In all experiments, repetition rates of $1 \sim 50 \mathrm{~Hz}$, the energy density of $6 \mathrm{~J} / \mathrm{cm}^{2}$, and an ablation time of 30-900 sec were used. A lowest resistivity of $8.45 \times 10^{-5} \Omega \cdot \mathrm{cm}$ and an optical transmittance of more than $80 \%$ in the visible range of the spectrum were obtained for ITO (5 wt \%) films of approximately 300-nm thickness fabricated at a substrate temperature of $400^{\circ} \mathrm{C}$ and oxygen pressure of $10 \mathrm{~Pa}$. Smooth surfaces with an average surface roughness of $1.26 \mathrm{~nm}$ were observed by field-emission scanning electron microscopy (FESEM) and atomic force microscopy (AFM).
\end{abstract}

\section{1.はじめに}

近年，電子ディスプレイデバイスの分野では液晶ディ スプレイ (LCD) 及びプラズマディスプレイ (PDP) などフラットタイプのディスプレイが，数々の優れた特 徵を有することからブラウン管タイプ（CRT）に代わ り急速に普及し始めている. 最近では有機エレクトロル ミネッセンス (EL) が高品質な光を発することから次 世代フラットディスプレイとして大きな注目を浴びてい

* 平成13年10月18日 第42回真空に関する連合講演会で発表 (18P-58)

*1 大阪産業大学工学部電気電子工学科（干574-8530 大阪府大東市中垣 内 3-1-1)

*2 大阪府立大学工学部電子物理工学科（干593-8531 大阪府堺市学園町 1-1)
る. 現在, ディスプレイ用透明導電膜として実用化され ている材料のほとんどが ITO（酸化インジウムスズ） 薄膜で, その他の用途では $\mathrm{SnO}_{2}, \mathrm{AZO}$ (アルミをドー プした酸化亜鉛) 及び $\mathrm{GZO}$ ( $\mathrm{Ga}$ をドープした酸化亜鉛) 薄膜などがある。また，透明導電膜を作製する手段とし て種々成膜法が考案されてきたが，近年，高品質な透明 導電膜を容易に得る手法としてパルスレーザー堆積法 （PLD 法）が注目され，数多く報告されてきた ${ }^{1-8)}$. 最 近ではPLD法で極めて低い抵抗率 $10^{-5} \Omega \cdot \mathrm{cm}$ 台を有する ITO 透明導電膜が作製された ${ }^{9-11)}$. しかしながら透明導 電膜を作製する手段として PLD 法の実用化を目指した とき，堆積レートが低く大面積化が困難であることが問 題となり現在解決方法が模索されている. そこで, 著者 らは従来の PLD 法で用いられるレーザーより高出力・ 
Table 1 Preparation conditions

\begin{tabular}{c|l|c}
\hline \hline \multicolumn{1}{c|}{ Laser } & \multicolumn{1}{|c}{ Laser Energy } & $300 \mathrm{~mJ}$ \\
\hline $\begin{array}{c}\text { ArF Excimer } \\
\text { Laser } \\
\lambda=193 \mathrm{~nm}\end{array}$ & $\begin{array}{l}\text { Repetition Rate } \\
\text { Laser Energy } \\
\text { Density }\end{array}$ & $\begin{array}{c}\mathrm{Hz} \sim 50 \mathrm{~Hz} \\
6 \mathrm{~J} / \mathrm{cm}^{2}\end{array}$ \\
\hline \multirow{5}{*}{ Chamber } & Target & ITO $\left(5 \mathrm{wt} \% \mathrm{SnO}_{2}\right)$ \\
& Substrate & Corning \#7059 \\
& Target to Substrate & $10 \mathrm{~mm} \sim 80 \mathrm{~mm}$ \\
& Substrate & $400^{\circ} \mathrm{C}$ \\
& Bemperature & $\sim 10^{-4} \mathrm{~Pa}$ \\
& Gas Pressure & $10^{-1} \sim 10 \mathrm{~Pa}\left(\right.$ in $\left.\mathrm{O}_{2}\right)$ \\
\hline & Ablation Time & $30 \mathrm{sec} \sim 900 \mathrm{sec}$ \\
\hline
\end{tabular}

高繰り返し周波数の $\mathrm{ArF}$ エキシマレーザー用い, ITO 透明導電膜を作製することを提案した ${ }^{12-14)}$. その結果， 従来に比べて約87倍（当研究室比）の高堆積レート化が 達成でき, さらに膜厚約 $300 \mathrm{~nm}$ で $10^{-5} \Omega \cdot \mathrm{cm}$ 台の極め て低い抵抗率之 $90 \%$ 以上の高い可視光平均透過率（波長 $400 \sim 700 \mathrm{~nm}$ の透過率の平均値）および表面平均粗さ $\mathrm{Ra}$ が1.0 nm 前後の平滑な膜が得られた。 また，この高 品質な ITO 透明導電膜は再現性良く作製できることも 分かったのでこれらの結果を報告する.

\section{2. 実験方法}

成膜は Table 1 の条件で行った. ITO 薄膜はコーニ ング＃7059ガラス基板に成膜し，基板温度は $400^{\circ} \mathrm{C}$ 一定 とした、実験に用いたレーザーは波長193 nmの ArF エ キシマレーザー（LAMDAPHISIK 社, LPX-305i）で 最大パルス出力は $500 \mathrm{~mJ}$, 最高繰り返し周波数は $50 \mathrm{~Hz}$ の能力を有するが，本実験では $300 \mathrm{~mJ}, 30 \mathrm{~Hz}$ を用い た.レーザービームは石英レンズでスポット径を約 $1 / 20$ に絞りターゲットに集光させエネルギー密度約 $6 \mathrm{~J} / \mathrm{cm}^{2}$ で用いた.ターゲットは $\mathrm{In}_{2} \mathrm{O}_{3}$ に $\mathrm{SnO}_{2}$ を $5 \mathrm{wt} \%$ 添加し た純度 $99.999 \%$ の $50 \mathrm{~mm} \phi \times 5 \mathrm{~mm}$ 厚の焼結体（フルウ チ化学株式会社製) を用い, パソコン制御のターゲット ローテーターでレーザービームが一個所に集中しないよ らに毎分 1 回転の速度で常時回転させながら成膜した. ターゲットと基板間の距離は今回成膜レートを変化させ るため $10 〜 80 \mathrm{~mm}$ と大きく変化させた．屯た，薄膜の 酸化度合いを調べるため酸素分圧を $10^{-1} \sim 10 \mathrm{~Pa}$ と大き く変化させた. その他の成膜条件は Table 1 に示す通り で，成膜装置は既に報告しているパルスレーザー堆積装 置と基本的に同様な構成となっている2-7,11-14).

膜の評価法は次の通りである, 膜厚測定は段差式膜厚 計 (KLA TENCOR 社, P-10), 抵抗率などの電気的特

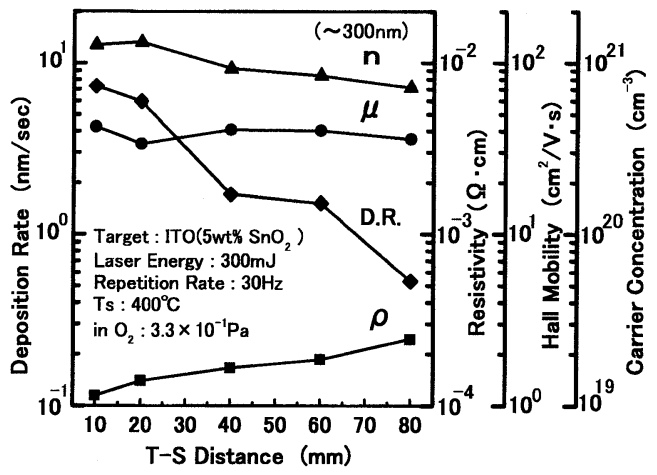

Fig. 1 The dependence of resistivity, carrier concentration, Hall mobility and deposition rate on the target-substrate distance for ITO ( $5 \mathrm{wt} \%$ ) films of approximately $300-\mathrm{nm}$ thickness. The substrate temperature was kept at $400^{\circ} \mathrm{C}$ and the oxygen pressure at $3.3 \times 10^{-1} \mathrm{~Pa}$ during deposition.

性はvan der Pauw を用いたホール効果測定装置（BIOー RAD 社, HL5500PG), 透過率などの光学的特性は自記 分光光度計（日立，U-3500）を用いた。 また，表面・ 断面観察は高分解能電界放出型走査電子顕微鏡（日立, $\mathrm{S}-4700$, 以下 $\mathrm{FE}-\mathrm{SEM}$ ）抌よび原子間力顕微鏡 (Topometrix 社, TMX-2000, 以下 AFM) で行なった.

\section{3. 実験結果及び考察}

Fig. 1 に Table 1 の条件下で酸素分圧を $3.3 \times 10^{-1} \mathrm{~Pa}$ とし ITO 透明導電膜を作製したとさの電気的特性およ び堆積レートのターゲット基板間距離依存性を示す.こ れより堆積レートは, ターゲット基板間距離を近づける ほど増加し， $10 \mathrm{~mm}$ のときに $7.3 \mathrm{~nm} / \mathrm{sec}$ と極めて大き

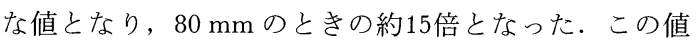
は当研究室で今まで報告してきた通常の堆積レートの值 の約 87 倍となった ${ }^{12)}$. 従って, 膜厚 $200 〜 300 \mathrm{~nm}$ の ITO 透明導電膜を作製するには成膜時間は約 $30 \sim 40 \mathrm{sec}$ しか必要とせず大面積化に繋がる極めて高速な成膜が可 能であることが分かった。 また, ターゲット基板間距離 を近づけるとキャリア密度とホール移動度が増加し，そ のため抵抗率は減少した，そしてターゲット基板間距離 $10 \mathrm{~mm}$ のとき抵抗率 $1.15 \times 10^{-4} \Omega \cdot \mathrm{cm}$ の良好な值が得ら れた.しかしながら，このとき自記分光光度計を用いた 透過率のスペクトル測定の結果, 可視光平均透過率は 74.2\%の值しか得られなかった。

そこで, その原因を調べるために FE-SEMにより表 面 SEM 像执よび AFMにより表面平均粗さを測定し た. その結果をFig. 2 に示す. Fig. 2(a)，(b)拉よび(c) はそれぞれターゲット基板間距離が $40 \mathrm{~mm}, 20 \mathrm{~mm}$ 括 


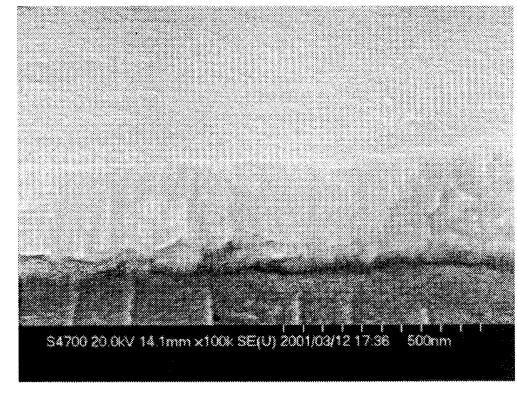

\section{(a)}

T-S Distance : $40 \mathrm{~mm}$

$\mathrm{Ra}: 1.25 \mathrm{~nm}(10 \mu \mathrm{m} \times 10 \mu \mathrm{m})$

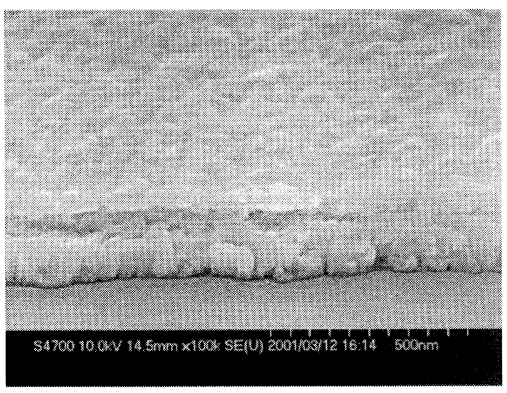

T-S Distance : $20 \mathrm{~mm}$

$\mathrm{Ra}: 2.85 \mathrm{~nm}(10 \mu \mathrm{m} \times 10 \mu \mathrm{m})$

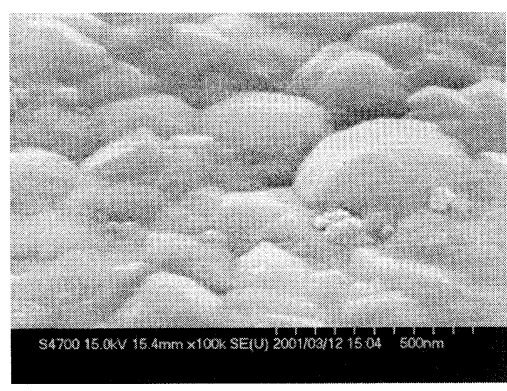

T-S Distance : $10 \mathrm{~mm}$

$\mathrm{Ra}: 11.48 \mathrm{~nm}(10 \mu \mathrm{m} \times 10 \mu \mathrm{m})$

Fig. 2 High-resolution SEM images obtained for ITO ( $5 \mathrm{wt} \%$ ) films fabricated under oxygen pressure of $3.3 \times 10^{-1} \mathrm{~Pa}$ and $\mathrm{T}-\mathrm{S}$ distance of (a) 40 $\mathrm{mm}$, (b) $20 \mathrm{~mm}$ or (c) $10 \mathrm{~mm}$.

よび10 mm のときの結果である(尚60 $\mathrm{mm}$ と $80 \mathrm{~mm}$ は, ほぼ40 mm のときと同様の結果であった).これより， 明らかにターゲット基板間距離を $20 \mathrm{~mm}$ に近づけると 表面形態が悪化することが明確に分かった（表面平均粗 さ $\mathrm{Ra}$ の值が $40 \mathrm{~mm}$ のときの $1.25 \mathrm{~nm}$ から $2.85 \mathrm{~nm}$ と大 きくなった).さらに10 mm まで近づけると極めて大き な粒径の山凸が存在し表面形態が大きく荒れることが分 かった（Raの值が $11.48 \mathrm{~nm})$.これより粒径サイズは分 光器の測定波長つまり可視光域の入射光の波長と近いた

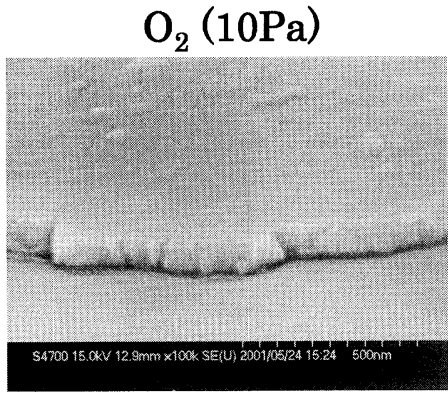

(a)

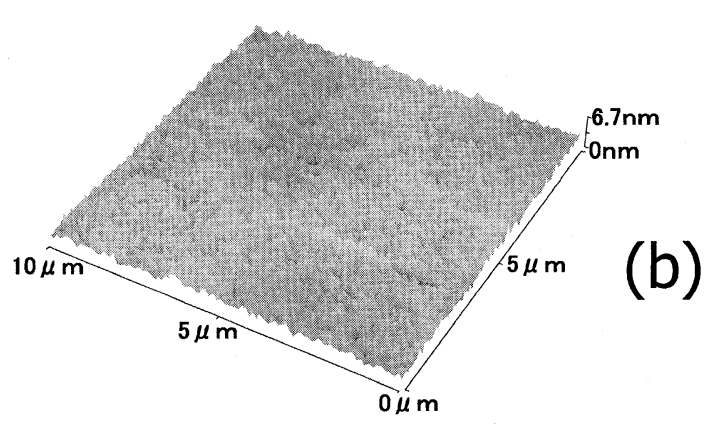

$\mathrm{Ra}: 1.26 \mathrm{~nm}(10 \mu \mathrm{m} \times 10 \mu \mathrm{m})$

Fig. 3 High-resolution SEM image (a) and AFM image, (b) obtained for the ITO (5wt\%) film deposited under an oxygen pressure of $10 \mathrm{~Pa}$ and the $\mathrm{T}-\mathrm{S}$ distance of $10 \mathrm{~mm}$.

め透過率の減少に繋がったと考えられる，尚，委た， ITO 薄膜の種々の特性に打いて膜中の Sn 濃度の影響を 調べるためEDS 測定を行った。その結果ターゲット基 板間距離にほとんど依存しないで一定值を示すことが分 かった。

そこで著者らは，以前の実験結果 ${ }^{12)}$ から表面形態は大 きく酸素分圧に依存することが判明しているので, 酸素 分圧を変化させて同様の実験を行った。

次に最も良好な電気的特性を示したターゲット基板間 距離10 mmの条件で成膜した場合に酸素分圧を通常の 約30倍の $10 \mathrm{~Pa}$ に増加させたときの FE-SEM 像と AFM 像を Fig. 3 に示す.これより顕著に表面形態が改善さ れることが分かった．AFMにより測定した表面平均粗 さ Raの值は Fig. 1 および Fig. 2 のターゲット基板間距 離が $40 \mathrm{~mm}$ ～ $80 \mathrm{~mm}$ のときの值とほぼ同じ1.26 nm が得 られた。このときの電気的特性および光学的特性を $\mathbf{T a}$ ble 2 に示す.ここでの試料番号とは実験の回数を表 し, 全部で 4 回行い, そのらちの 3 回分を記載した.

これより抵抗率は膜厚 $300 \mathrm{~nm}$ 前後で $10^{-5} \Omega \cdot \mathrm{cm}$ 台の 極めて低い抵抗率が得られた。 また，このときの可視光 平均透過率は80 90\%の值を示し, 表面形態の観察より 平滑な膜 ( $\mathrm{Ra}$ は約 $1.25 \mathrm{~nm}$ ) が得られた. 
Table 2 Electrical and optical properties of ITO (5 wt \%) film grown in oxygen pressure of $10 \mathrm{~Pa}$ at $\mathrm{T}-\mathrm{S}$ distance of $10 \mathrm{~mm}$

\begin{tabular}{c|c|c|c|c|c}
\hline \hline Sample number & $\begin{array}{c}\text { Resistivity } \\
(\Omega \cdot \mathrm{cm})\end{array}$ & $\begin{array}{c}\text { Hall Mobility } \\
\left(\mathrm{cm}^{2} / \mathrm{V} \cdot \mathrm{s}\right)\end{array}$ & $\begin{array}{c}\text { Carrier } \\
\text { Concentration } \\
\left(\mathrm{cm}^{-3}\right)\end{array}$ & $\begin{array}{c}\text { Average } \\
\text { Transmittance } \\
(\%)\end{array}$ & $\begin{array}{c}\text { Thickness } \\
(\mathrm{nm})\end{array}$ \\
\hline 1 & $8.45 \times 10^{-5}$ & 53.5 & $1.38 \times 10^{21}$ & 83.7 & 315. \\
2 & $9.72 \times 10^{-5}$ & 58.9 & $1.09 \times 10^{21}$ & 82.7 & 321 \\
3 & $8.78 \times 10^{-5}$ & 51.6 & $1.38 \times 10^{21}$ & 90.7 & 281 \\
\hline
\end{tabular}

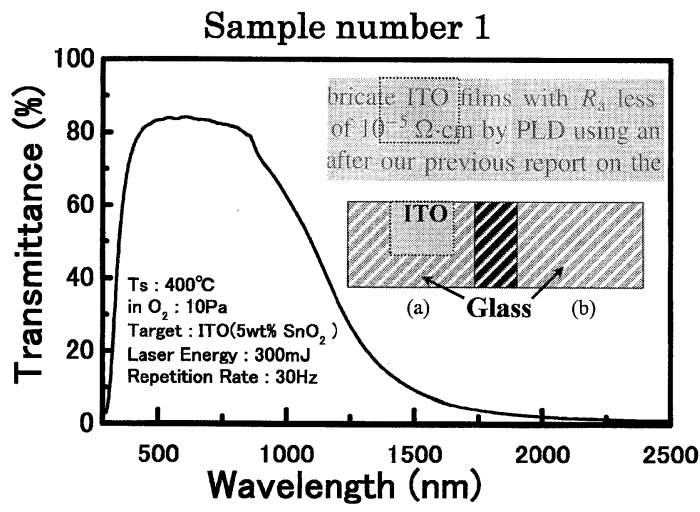

Fig. 4 Optical transmittance spectra of sample No. 1 listed in Table 2. The inset gives the proof of high transmittance.

Fig. 4 に Table 2 の試料番号1の透過率スペクトルを 示す. 図中の挿入図は, 実際に書類（普通紙印刷物）の 上に ITO 透明導電膜を置きデジタルカメラで撮影した 写真である.（a） ITOを部分的に（写真点線内）堆積 させたガラス基板で，(b)はなにも堆積させていないが ラスである，これより，印刷物の文字が通常ガラスとほ とんぞ同様に明確に読み取ることができ高い透過率を有 していることが分かった．透過率のスペクトル図より自 由電子のプラズマ共鳴現象により長波長側 $(\lambda=800 \mathrm{~nm}$ 以上）で急激に減少し，大きなキャリア密度が得られて いることが分かった.

このよらな低い抵抗率と高い可視光平均等透過率を有 した ITO 透明導電膜は, 本実験手法において約70〜80 \%の高い確率で再現性良く作製できることが分かった。

\section{4. をとめ}

レーザーエネルギー密度 $6 \mathrm{~J} / \mathrm{cm}^{2}$, 繰り返し周波数 30 $\mathrm{Hz}$ の高出力 $\mathrm{ArF}$ エキシマレーザーを用いた PLD 法で ITO 透明導電膜を作製し以下の結果を得た.

1）ターゲット基板間距離を $80 \mathrm{~mm}$ から $10 \mathrm{~mm}$ まで 近つけると, 堆積レートは急激に増加し(約15倍), 抵抗率は単調に減少した.
2）ターゲット基板間距離を $10 \mathrm{~mm}$ とした場合，表 面形態が大きく荒れ，透過率が減少した.

3）ターゲット基板間距離を $10 \mathrm{~mm}$ とし酸素分圧を 通常の $3.3 \times 10^{-1} \mathrm{~Pa}$ から約30倍の $10 \mathrm{~Pa}$ に増加した とき, $10^{-5} \Omega \cdot \mathrm{cm}$ 台の低抵抗率と高い透過率拈よび 平滑な表面形態を有する ITO 透明導電膜が再現性 良く作製できた。

\section{〔文献〕}

1) J. P. Zheng and H. S. Kwok: Appl. Phys. Lett., 63 (1993) 1.

2) A. Suzuki, T. Matsushita, Y. Sakamoto, N. Wada, T. Fukuda, H. Fujiwara and M. Okuda: Jpn. J. Appl. Phys., 35 (1996) L56.

3）鈴木晶雄 - 松下辰彦 - 坂本吉亮 · 和田直己 . 奥田 昌宏 : 真空, 39 (1996) 331 .

4) A. Suzuki, T. Matsushita, N. Wada, Y. Sakamoto, T. Fukuda, H. Fujiwara and M. Okuda: Jpn. J. Appl. Phys., 35 (1996) 5457.

5）鈴木晶雄 - 松下辰彦 - 福田智也 - 藤原秀規 - 奥田 昌宏：電気学会論文誌 A, 117 (1997) 405.

6）鈴木晶雄 - 藤原秀規 - 福田智也 - 青木孝憲 - 松下 辰彦・奥田昌宏 : 真空, 41 (1998) 270.

7) A. Suzuki, T. Matsushita, T. Aoki, Y. Yoneyama and M. Okuda: Jpn. J. Appl. Phys., 38 (1999) L71.

8) H. Kim, C. M. Gilmore, A. Pique, J. S. Horwitz, H. Mattoussi, H. Murata, Z. H. Kafafi and D. B. Chrisey: J. Appl. Phys., 86 (1999) 6451.

9) Ohta, M. Orita, M. Hirano, H. Tanji, H. Kawazoe and H. Hosono: Appl. Phys. Lett., 76 (2000) 2740.

10) F. O. Adurodija, H. Izumi, T. Ishihara, H. Yosioka, M. Motoyama and K. Murai: Jpn. J. Appl. Phys., 39 (2000) L377.

11) A. Suzuki, T. Matsushita, T. Aoki, Y. Yoneyama and M. Okuda: Jpn. J. Appl. Phys., 40 (2001) L401.

12）守昭人, 他: 応用物理学会学術講演会予稿集 (平成13年春) $31 \mathrm{a}-\mathrm{P} 15-22$.

13）守昭人, 他：応用物理学会学術講演会予稿集 (平成13年秋) $13 \mathrm{a}-\mathrm{ZX}-4$.

14) A. Suzuki, T. Matsushita, T. Aoki, A. Mori and M. Okuda: 2nd International Symposium on Transparent Oxide Thin Films for Electronics and Optics, November 8, (2001). 